\title{
FERRAMENTAS JORNALÍSTICAS NA EDUCAÇÃO Uma rádio online para jovens
}

\author{
Maria José Brites \\ Universidade Lusófona do Porto e Centro de Estudos de Comunicação e Sociedade, Porto e Braga, \\ Portugal

\section{Sílvio Correia Santos} \\ Universidade de Coimbra, Ceis20 e Centro de Investigação Media e Jornalismo, Coimbra e Lisboa, \\ Portugal
}

\author{
Ana Jorge \\ Centro de Estudos de Comunicação e Cultura / Universidade Católica Portuguesa e CICS.Nova, \\ Lisboa, Portugal
}

\section{Daniel Catalão}

Universidade do Porto e Universidade Lusófona do Porto, Porto, Portugal

\begin{abstract}
Resumo A relação entre jornalismo e educação configura um campo ainda pouco explorado, embora a prática de princípios e técnicas jornalísticas se constitua também como ferramenta pedagógica. Neste artigo, partimos de um estudo de caso com rádio online, desenvolvido junto de comunidades juvenis, e recorremos a observação participante, entrevistas e grupos focais conduzidos no âmbito do projeto RadioActive Europe (2013-14), para mostrar como os jovens participantes assumem na vida quotidiana, e particularmente na escolar, papéis semelhantes aos usados nos contextos da rádio. A aprendizagem pela ação, contudo, necessita de processos de intervenção duradouros para que essa transposição dos papéis assumidos no projeto seja mais perene, dinâmica e fluida nos processos da vida pessoal.
\end{abstract}

Palavras-chave: jornalismo, educação para os media, rádio, jovens, online.

Abstract The relationship between journalism and education remains in a yet weakly explored camp, although journalism can embody a pedagogical tool, oriented to the practice of journalistic concepts and techniques. In this article, we explore a case-study of an online radio developed with youth communities, using participant observation, interviews and focus groups conducted in the scope of the project RadioActive Europe (2013-14). We argue that these young participants take similar roles in daily life and particularly in school to those used in contexts of radio participation. Learning through action, however, implies long lasting intervention processes so that the transposal of roles taken up in the project may be more perennial, dynamic and fluid in the personal life processes.

Keywords: journalism, education for media, radio, youngs, online.

Résumé Le rapport entre journalisme et éducation est un domaine encore peu exploré, même si l'application des principes et des techniques journalistiques constitue aussi un outil pédagogique. Cet article part de l'étude de cas d'une radio en ligne développée auprès de groupes de jeunes, en utilisant l'observation participante, les entretiens et les groupes cibles dans le cadre du projet RadioActive Europe (2013-14), pour montrer comment les jeunes participants jouent dans leur vie quotidienne et en particulier à l'école des rôles semblables à ceux utilisés dans les contextes de la radio. Cependant, l'apprentissage par l'action a besoin de processus d'intervention durables pour que cette transposition des rôles joués dans le projet soit plus pérenne, dynamique et fluide dans les processus de la vie personnelle.

Mots-clés: journalisme, éducation aux médias, radio, jeunes, en ligne.

Resumen La relación entre periodismo y educación configura un campo poco explorado aún, aunque la práctica de principios y técnicas periodísticas se constituya también como herramienta pedagógica. En este artículo, partimos de un estudio de caso con radio online desarrollado con comunidades juveniles y recurrimos a la observación participativa, entrevistas y grupos focales conducidos en el ámbito del proyecto 
RadioActive Europe (2013-14), para mostrar como los jóvenes participantes asumen en la vida cotidiana y, particularmente en la escolar, papeles semejantes a los usados en los contextos de la radio. Sin embargo, el aprendizaje obtenido por la práctica necesita de procesos de intervención duraderos para que esa transposición de los papeles asumidos en el proyecto sea más perene, dinámica y fluida en los procesos de la vida personal.

Palabras clave: periodismo, educación para los media, radio, jóvenes, online.

\section{Jornalismo e comunidade}

O jornalismo, autonomizado como profissão há um século, tem enfrentado grandes desafios. Essa pressão crescente tem-se refletido numa discussão cada vez mais intensa acerca de uma tendência inversa de desprofissionalização, provocada por alterações de definição da profissão, bem como por mudanças económicas e tecnológicas, entre outras. São, precisamente, a natureza e o impacto das mutações nas interações sociais e nos processos de circulação e consumo de informação que nos levam a apontar o foco à possível e importante ligação do jornalismo à comunidade. Esta é uma relação nuclear, se pensarmos o jornalismo como bem público, também apropriado pelas comunidades que tomaram para si as responsabilidades de passar a palavra da notícia e servir as pessoas. É nesse contexto que nos importa conceber processos inspirados no jornalismo profissional como ferramentas facilitadoras de aprendizagens e de participação dos próprios cidadãos.

Com efeito, a conceção de jornalismo comunitário, ${ }^{1}$ que se assume como influência particular, começou por ser formada a partir de uma prática informativa exercida por jornalistas e ligada à imprensa em comunidades pequenas (Reader, 2012). O comunitarismo do jornalismo cívico está associado a uma "vida solidária" (Mesquita, 2003: 22), no sentido da relevância inerente à comunidade encontrada nas práticas cívicas do jornalismo.

A forma como a sociedade olha o chamado jornalismo comunitário mudou bastante por efeito da entrada na era digital. Ancorado numa visão do jornalismo como valor público e dos novos media como plataformas participativas, um dos debates mais recorrentes na atualidade centra-se na expectativa de um aumento da participação cívica através dos meios online. Na verdade, a "interseção do jornalismo com a participação democrática gera novas práticas - e temas. Certamente que a internet, como domínio de socialização quotidiana, se torna topografia primordial para a participação" (Dahlgren, 2013: 177).

Nesta linha, o nosso foco neste artigo recai sobre uma rádio online produzida por jovens, discutindo as oportunidades que o uso de ferramentas oriundas do campo do jornalismo pode ter em comunidades excluídas ou em risco de exclusão. Esta reflexão tem como base a investigação-ação participativa que decorreu entre

Termo cunhado nos anos 50 por Kenneth R. Byrerly (Reader, 2012). 
2013 e 2014, no âmbito do RadioActive Europe, ${ }^{2}$ que em Portugal foi aplicado junto de jovens em situação ou risco de exclusão, tanto no domínio da educação como na vida profissional ativa.

A perspetiva que adotamos centra-se, sobretudo, nas audiências participativas e na possibilidade de os programas de educação para os media poderem sustentar-se na prática e reflexão de inspiração jornalística; isto é, constituindo-se, simultaneamente, como plataformas privilegiadas de informação de proximidade (embora não jornalística no sentido legal do exercício da profissão em Portugal) e como veículos para uma melhor apropriação dos media e da literacia nas diferentes frentes da vida quotidiana. Para tal, começamos por discutir as possibilidades da tecnologia, aprendizagem, competências e identidades comunitárias. O artigo reflete ainda sobre a literacia mediática e a aprendizagem não formal, avançando neste seguimento para uma caracterização de projetos concretos que associam o jornalismo à literacia. Tendo em conta esta revisão de literatura e os aspetos que encontramos na observação empírica, avançamos com estas duas questões de partida: Que tipo de repercussão pode ter o uso de técnicas jornalísticas como ferramentas educativas junto de comunidades juvenis? Que tipo de papéis assumem estes jovens na rádio e como se repercute isso no seu quotidiano, muito em especial na escola?

\section{Tecnologia e comunidades: facilitação de saberes}

A participação através dos media, e em particular em contextos de inspiração jornalística, nem sempre foi reconhecida como elemento valorativo, sobretudo na educação tradicional. Porém, o futuro parece apontar numa direção diferente, na qual os media são considerados simultaneamente nos processos educacionais tradicional e não tradicional (Stephenson, 2013). O fator decisivo nessa mudança tem sido a migração para o contexto online.

Focando-nos na esfera não tradicional, lugar da educação fora da escola, uma das dimensões mais interessantes da ligação entre a tecnologia e a comunidade é a possibilidade de aquela fomentar a aprendizagem no contexto coletivo, na comunidade, tirando partido do seu poder social (Wenger, White e Smith, 2009). A ideia de comunidade remete-nos para imagens de sentimentos, identidade, pertença, causas comuns e partilha (Chaskin, 2013). A comunidade de prática conduz-nos para a ideia de que os membros de uma comunidade são engajados entre si por interesses particulares ou áreas geográficas específicas, o que faz com que se envolvam de forma natural. São essas relações entre os indivíduos e a sua participação na comunidade que consubstanciam de certa forma uma dada identidade comum, normas partilhadas e interações concretas (Chaskin, 2013). A tecnologia constitui-se agora, precisamente, como uma forma de

2 RadioActive Europe (531245-LLP1-2012-1-UK-KA3-KA3MP), financiado pela Comissão Europeia, através do Lifelong Learning Programme. 
mediar essa construção comunitária, muitas vezes fragmentada pelo tempo, pelo espaço e pela diversidade dos participantes (Wenger, White e Smith, 2009).

A extensão atual dos media digitais pode facilitar os processos participatórios. No entanto, as desigualdades sociais em ligação com as digitais produzem assimetrias nas oportunidades de vida concretas, como emprego, salários, tratamentos médicos ou, por exemplo, relações sociais, argumentam Van Dijk e Van Deursen (2014). As pessoas com competências digitais mais avançadas usam o computador e a internet com mais frequência, durante mais tempo e em diversos contextos de prática. Os autores apontam ainda para a relevância dos contextos digitais nos curricula escolares e para o facto de que a exclusão das competências digitais sugere uma exclusão social e significa barreiras de participação para quem manifesta dificuldades em lidar com as múltiplas tecnologias digitais. Pensando em soluções articuladas com os contextos sociais, os autores holandeses consideram que a promoção de competências sociais em contexto de vida pode ser uma solução mais viável: "possibilitar um emprego [onde existam computadores] pode ser uma melhor solução para problemas de competência digital do que dar um computador ou um curso de internet" (Van Dijk e Van Deursen, 2014: 146).

As competências de literacia, enfatizadas por Paula Lopes, são " 'conhecer e compreender' (dois eixos de análise: um centrado no conhecimento; outro mais reflexivo), 'avaliar criticamente' e 'criar para comunicar'" (Lopes, 2015: 49). Esta última dimensão relaciona-se com a utilização das esferas mediáticas para produzir conteúdos públicos. Na verdade, a competência para a criação de conteúdo tem sido indicada como um estádio avançado das competências digitais (Livingstone e Helsper, 2007; Van Dijk e Van Deursen, 2014; Lopes, 2015).

O conceito de "competências estratégicas" de Van Dijk e Van Deursen (2014) remete para um outro nível a ter em conta nas sociedades atuais e que tem que ver com as vantagens colaterais e enraizadas no quotidiano que cada cidadão pode retirar da tecnologia. Também Manuel Pinto aponta nesse sentido, ao dizer que "o cidadão do século XXI não é o que detém a tecnologia, mas sim o que a consegue compreender e a usa com vantagem para enfrentar os desafios que a vida tem a oferecer" (2015: 22).

Na verdade, apesar do trabalho no RadioActive no nível das competências de criação, isso não significa que estes jovens possuam realmente competências em todos os níveis desta "escada" até ao topo nas competências digitais (Livingstone e Helsper, 2007), mas sobretudo que usamos este meio para melhorar as suas competências mediáticas e cívicas. Pereira, Pinto e Moura (2015), num recente estudo sobre competências mediáticas em Portugal, indicam precisamente a necessidade de se analisar e compreender melhor as competências mediáticas na sua ligação e transferência aos diversos planos da vida quotidiana que se cruzam com os media, onde a investigação ainda é escassa.

Esta perspetiva relaciona-se, aliás, com a Recomendação do Parlamento Europeu e do Conselho de 18 de dezembro de 2006, sobre as competências essenciais para a aprendizagem ao longo da vida, incluindo comunicação na língua materna e em línguas estrangeiras, competência digital, aprender a aprender, competências sociais e cívicas, espírito de iniciativa e espírito empresarial e, entre 
outras, sensibilidade e expressão culturais. Este conjunto de competências, que constituiu um dos pilares de condução do RadioActive, aponta para um cruzamento entre o plano mediático e competências essenciais de desenvolvimento pessoal, para um horizonte do exercício de uma cidadania ativa e para a inclusão social e emprego.

\section{Literacia mediática e aprendizagem não formal: oportunidades na comunidade}

Apesar do défice de atenção da sociedade hiperligada, o acesso à informação e o respetivo consumo constituíram-se como processos de socialização intrínsecos às dinâmicas quotidianas. Efetivamente, um princípio de correspondência entre saber e poder tornou-se, paulatinamente, num dos pilares ideológicos e políticos centrais dos nossos dias. No entanto, a ecologia comunicacional é hoje francamente mais complexa na sua teia de inter-relações. O jornalismo é um processo tradicionalmente emancipatório de construção de ferramentas que permitem desenvolver uma consciência crítica do mundo; é, na linha de Buckingham (2012 [2003]), uma prática mental ou social mais poderosa, porque mais crítica.

Se perspetivado do ponto de vista da receção, este processo de relação social com os media, que permite uma maior capacidade de intervenção social, mesmo que a nível micro, pode ser abordado no âmbito da literatura em torno da literacia dos media. Embora abordada frequentemente do ponto de vista das competências, a literacia não pode reduzir-se a essa dimensão; tal como argumenta Livingstone, é preciso ter em conta "a relação interpretativa com um texto complexo, simbolicamente codificado e tecnologicamente mediado" (2004: 8). É por isso que, na era da hiperconectividade, a autora sugere não uma, mas várias literacias, que existem em função da relação com o respetivo meio. Na realidade, há um novo desafio conceptual neste campo e a verdade é que a ideia de literacia digital não é ainda muito estável, dependendo dos contextos e dispositivos.

O termo relaciona-se com a educação para os media ou, na referência mais comum no Brasil, a educomunicação, reportando-se ao conjunto das ações destinadas a integrar práticas, ao estudo dos mecanismos de comunicação, a observar como os media atuam em sociedade e a procurar formas de colaboração. Significa criar e reforçar ecossistemas comunicativos e educativos e aperfeiçoar a expressão das ações comunicativas (Lahni e Coelho, 2008: 213-214). Manuel Pinto (2014) remete-nos para a ideia de que as práticas comunicativas e participativas no contexto mediático estão intrinsecamente ligadas à pluralidade de meios e também à sociabilidade dos meios em que se inserem as práticas comunicativas. Mario Kaplún (2011) aponta para este espaço alargado entre a comunicação e a educação, um ambiente em que as práticas comunicativas estão para além dos media em si mesmos. A comunicação pode até ser gerada pelos media mas propaga-se socialmente, em contexto onde a comunicação se divulga e integra com forma de educação, proporcionando uma pedagogia a partir da comunicação e também uma comunicação a partir da pedagogia (Kaplún, 2011). 
Os contextos sociais informais, que têm um intuito claro de ligação aos contextos não formais de educação, acabam por conseguir uma dinâmica social muito produtiva, pois seguem uma procura do melhor de dois mundos. Os processos de educação para os media "localizados", centrados em projetos nos quais as pessoas e as comunidades têm oportunidade de trabalhar, são mais dinâmicos e consentâneos com as vicissitudes da vida quotidiana. Nestes espaços comunitários personalizados podemos conceber literacias "localizadas", experimentadas e adaptadas ao contexto em que as práticas ocorrem quotidianamente e nos contextos da cultura local (Underwood, Parker e Stone, 2013). Com efeito, nos ambientes informais e não formais a aprendizagem pode ser mais facilmente negociada ( $i d .$, ibid.).

Note-se que a intenção não é valorizar um ambiente mais que o outro, mas sim encontrar complementaridades, sinergias e soluções mais profícuas. $\mathrm{O}$ novo reforço na aprendizagem ao longo da vida e na vida quotidiana aponta para uma forma de pensamento sobre a aprendizagem muito para além da escola e da sala de aula. Estes contextos, identificados como "mundo real", por vezes levam a considerações rígidas e extremadas entre aprendizagem formal e não formal (Meyers, Erickson e Small, 2013: 356), quando a abordagem ideal será a de uma efetiva complementaridade (Brites, Jorge e Santos, 2014).

\section{Uso de ferramentas jornalísticas e literacia: um mapeamento de projetos e experiências junto de comunidades juvenis}

Esta ligação específica entre jornalismo e literacia - ambos processos emancipatórios do indivíduo e das comunidades - , agora também centrada nas capacidades de produção do público, tem encontrado duas vias: a do denominado jornalismo escolar e a de iniciativas estruturantes ligadas a empresas jornalísticas. No caso português, essa dupla articulação tem-se consumado sobretudo pela primeira via, embora existam algumas iniciativas de empresas jornalísticas, na realidade também algumas delas associadas ao jornalismo escolar. A mais antiga e continuada (embora atualmente numa fase de retração) é o projeto "Público na Escola", criado em 1989, por altura do lançamento do jornal e com uma marca de liderança e participação de jornalistas. Também o "Projeto de Educação para os Media" (2007-2011, em Castelo Branco), financiado pela Fundação para a Ciência e a Tecnologia e pelo semanário regional Reconquista (Tomé, 2014), se focou no uso dos jornais escolares impressos. Outros projetos mais recentes centram-se noutras propostas, como é o caso do "MediaLab" (Diário de Notícias e Jornal de Notícias), que foi concebido para jovens e adultos. $\mathrm{O}$ "MediaLab" tem recorrido a várias plataformas ligadas aos dois jornais, para proporcionar oficinas de curta duração sobre, por exemplo, como fazer uma primeira página. Por fim, importa indicar o projeto "Jornalismo na Escola", do Setúbal na Rede, que promovia visitas às escolas do distrito e publicava algumas das notícias feitas por alunos num espaço do portal reservado para esse efeito (Brinca, 2014: 486).

A European Newspaper Publishers' Association defende que "é muito importante que os jornais e os media noticiosos sejam parte deste debate da melhoria 
das capacidades de literacia para os media na Europa" (ENPA, 2013: 2). De forma geral, os principais públicos-alvo destas iniciativas têm sido grupos etários até aos 18 anos ou jovens adultos (até aos 24 anos). As estratégias passam por uma ligação multifacetada do jornalismo ao contexto educativo. Jornalistas dirigem-se a escolas secundárias ou atuam em laboratórios de media nas próprias empresas, são promovidas visitas aos media ou mesmo experiências em que os jovens colaboram na elaboração de edições de jornais, chegando a publicar artigos. Outra iniciativa é a criação de jornais "amostra" que têm o formato do jornal modelo mas que também têm indicações sobre como fazer uma publicação (desde conteúdos a procedimentos mais técnicos), servindo sobretudo como ferramentas de ensino em contexto escolar.

Com repercussão mundial, a World Association of Newspapers and News Publishers (WAN-IFRA) possui uma secção específica dedicada a esta temática Youth engagement $\mathcal{E}$ news literacy - e atribui os prémios The World Young Reader Prizes para laurear projetos de literacia para as notícias e de promoção da participação dos jovens. Alguns dos mais valorizados títulos da imprensa mundial, como The Washington Post, The New York Times e The Guardian, gerem programas de educação para as notícias.

Pensando os media como uma herança de um ideário de liberdade de pensamento e direito à livre expressão, eles são concebidos como uma ligação privilegiada entre o cidadão e as instituições democráticas, também proporcionando espaços de voz para os cidadãos comuns (Nunes, 2008). Assim, a implementação de media comunitários constitui-se frequentemente como a melhor intervenção possível quando se pretende contribuir para uma emancipação cívica em contextos mais vulneráveis. O projeto carioca "Viva Favela", que se baseia no uso de ferramentas jornalísticas diversas para a promoção da inclusão social e digital, é um exemplo disso mesmo. Uma participante do "Viva Favela", que tinha sido radialista comunitária, considera que a participação nestes media lhe confere um estatuto e, mais do que isso, permite que os moradores possam dialogar com outras comunidades (Nunes, 2008). Com efeito, os ganhos em torno das condições da vida quotidiana são maiores do que a mera divulgação dos trabalhos em si (id., ibid.) - um aspeto, aliás, que viríamos a encontrar também no RadioActive, como referiremos adiante. Projetos inseridos na comunidade, como o "Viva Favela", "atuam no sentido de colocar esse aparato tecnológico comunicacional e informacional ao serviço de projetos e objetivos previamente definidos pelos grupos sociais [...]. Os participantes aproximam-se da sua realidade quotidiana" (id., ibid.: 121).

Já Alexandre Barbalho explica que os projetos com jovens que usam os media para expressar as suas ideias sobre o mundo são muito diversos, mas têm em comum o facto de criarem entre eles "políticas de amizade" (2008: 165). Com efeito, Barbalho (2008) sublinha uma esfera que não é enfatizada na produção jornalística tradicional, mas que é essencial nestes projetos com essa influência: a dimensão afetiva (id., ibid.). Igualmente, Peter Dahlgren defende que "seríamos inconsequentes se negássemos o papel indispensável do lado afetivo do engajamento" (2009: 83-84). É neste sentido que importa considerar o lado afetivo das culturas cívicas quando pensamos na cultura quotidiana. 
Por vezes, o trabalho junto de grupos sem formação específica na área dos media resulta num inesperado desenvolvimento de novas perspetivas. As fases iniciais de formação - quando a metodologia as inclui - são momentos fulcrais no tipo de envolvimento de cada participante. Harshani Weerasinghe, uma participante de rádio comunitária no Sri Lanka, explica como as sessões de workshops iniciais foram muito importantes, em especial para uma pessoa que não tinha qualquer tipo de formação em media, e refere que essas sessões fizeram com que se sentisse alguém que "olha e perceciona o mundo de forma inovadora e com olhos refrescados através de um processo de comunicação num contexto intelectual [...]; esta formação foi uma oportunidade de olhar para a profissão de forma diferente, comparando com a educação [escolar]" (2012: 336). Depois disso, sentiu-se atraída pelo jornalismo profissional, tirou um curso de jornalismo e tornou-se jornalista e radialista num projeto de rádio, através da Fundação Gemidiriya, que viria a obter a primeira frequência oficial de rádio comunitária dada pelo governo do Sri Lanka. Quando pensa no feedback da comunidade, Weerasinghe (2012) recorda-se de os pais e o marido não reconhecerem a sua voz no ar. É neste sentido que consideramos que a literacia para o jornalismo tem uma ligação intrínseca com a literacia para a cidadania e com as culturas cívicas (Milner, 2009; Moeller, 2009; Mihailidis, 2012; Hobbs, Cohn-Geltner e Landis, 2011; Brites, 2015).

\section{Contexto de investigação}

Este artigo surge na sequência do RadioActive Europe, um projeto de investigação-ação, centrado na produção de rádio para a internet em contexto educativo não formal.

A metodologia de investigação ação-participação é inspirada pelo trabalho do pedagogo brasileiro Paulo Freire (Brites, Jorge e Santos, 2014) e, como tal, enquadra-se na Comunicação para o Desenvolvimento (C4D), que tem tido um incremento significativo desde 2005, focando-se no cruzamento da comunicação, empoderamento de comunidades e contextos dinâmicos de alteração social (Tufte, 2015). A C4D pressupõe vantagens em ir além da valorização da transmissão de informação, assentando nos contextos sociais em que as pessoas se inserem e vivem, dando uma outra dimensão à informação produzida e transmitida, nomeadamente pelas rádios feitas pela comunidade (Paula, 2012). Assim, o RadioActive propõe uma metodologia centrada nas particularidades de cada comunidade, de forma a que os participantes estejam ativamente presentes nos processos de discussão, análise e produção. Há, subjacente, um princípio nuclear de diálogo como forma de potenciar o desenvolvimento de competências e ferramentas.

Para tal, foi essencial que o RadioActive conhecesse os locais onde estava a atuar, para encontrar sinergias com eles e beneficiar das estruturas, atividades e vontades já existentes (Brites, Jorge e Santos, 2014). A estratégia adotada pelo RadioActive inspira-se, assim, na proposta de Paulo Freire: "ensinar não é transferir conhecimento, é criar as possibilidades para a sua produção" (2010: 22). Aliás, e ainda na linha do pensamento de Freire, é nas comunidades que devem ser 
encontrados os temas que têm que ver com as suas vivências e que podem ser discutidos (2010: 30). Como aponta Andrew Ravenscroft (2011), que tipo de diálogo é necessário e que formas e géneros estão implicados na realização de atividades que suportam essa rede de aprendizagem?

Em Portugal, o RadioActive foi implementado junto de jovens em situação ou risco de exclusão, tanto no domínio da educação como no da empregabilidade. A implementação foi feita no Porto e em Coimbra, em centros apoiados pelo Programa "Escolhas", que teve origem a 9 de janeiro de 2001, através da Resolução do

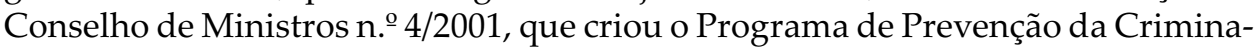
lidade e Inserção dos Jovens dos Bairros mais Vulneráveis dos Distritos de Lisboa, Setúbal e Porto. Nesta fase, o "Escolhas" já está na sua sexta geração (2016-18), tendo o programa sido alargado a todo o território nacional.

No terreno, o RadioActive empenhou-se na auscultação de necessidades e de capacidades encontradas nos centros envolvidos (quer dos técnicos, quer dos jovens). ${ }^{3}$ Numa primeira fase, foram identificados participantes que não tinham qualquer experiência de rádio online, mas também alguns que poderiam funcionar como catapultas de conhecimento devido a experiências anteriores em contexto escolar.

Para que o RadioActive se desenvolvesse sobre estes princípios, uma das primeiras fases do trabalho consistiu na problematização do que significa conceptualizar a mudança (Brites, Jorge e Santos, 2014). Por outras palavras, era necessário analisar e conhecer bem o grupo que iria construir o projeto, de forma a adaptá-lo à comunidade e ao contexto em que se inseria. Para isso, o RadioActive pretendeu focar a intervenção nos interesses e motivações pessoais, nas necessidades do grupo, nos conhecimentos digitais já existentes e nas práticas performativas em contexto online e off-line.

A implementação no terreno incluiu um plano de workshops técnicos dinamizados pela equipa de investigadores do RadioActive, em colaboração com os monitores dos centros de jovens, entre a primavera de 2013 e o final do ano de 2014 . Na fase inicial dos workshops, foi discutido em cada grupo o modelo editorial do projeto a desenvolver. Os workshops posteriores mostraram-se igualmente fundamentais, sobre os princípios e práticas da produção radiofónica e do jornalismo, abrangendo desde a prática do software de edição, ao aperfeiçoamento de técnicas vocais, à reportagem e à preparação de entrevistas, entre outros aspetos.

\section{Perguntas e orientações metodológicas}

Como indicámos na introdução, e decorrendo da problematização anterior, colocamos duas questões fundamentais neste artigo: Que tipo de repercussão pode ter o

3 Três centros em 2013 e um em 2014 (sobre o qual não incidiu a análise, por ter entrado mais tarde): o que identificamos como centro 1 (Porto) já tinha tido experiências anteriores de uso de rádio escolar; o centro 2 (Porto) e o centro 3 (Coimbra) nunca tinham desenvolvido experiências de rádio. 
uso de técnicas jornalísticas como ferramentas educativas junto de comunidades juvenis? Que tipo de papéis assumem estes jovens na rádio e como se repercute isso no seu quotidiano, muito em especial na escola?

Não sendo estas questões de partida para o projeto RadioActive em si, logo no final do primeiro ano - quando se tinha finalizado a formação inicial e cada um dos três centros iniciais tinha produzido e emitido dois programas de rádio - começou a emergir esta ligação estreita entre o que são os conceitos e os instrumentos oriundos do jornalismo e a natureza educativa que eles podem suportar. Em consequência, neste artigo a análise decorre de observação participante feita na segunda metade de 2013, concentrada nos contextos já identificados e no trabalho que foi feito até aí. Além disso, para responder às questões específicas com uma compreensão mais aprofundada do contexto, realizaram-se entrevistas (individuais e coletiva) e grupos focais, com técnicos e jovens (em janeiro de 2014, no Porto, nos centros 1 e 2; e em abril de 2014, no Porto, em ambos os centros, e em Coimbra, no centro 3). Os guiões centraram-se na avaliação das expectativas e na perceção dos resultados face ao RadioActive, muito em especial no cruzamento com as competências jornalísticas, comunicacionais, técnicas e de organização. Estas competências foram discutidas e definidas por um conjunto de investigadores com orientações diversas, inclusive jornalistas com carteira profissional. Quer as notas de campo decorrentes da observação participante, quer as entrevistas e grupos focais constituem elementos de análise não só do progresso do projeto como também das reflexões pessoais que a rádio educativa tem no quotidiano destes participantes.

\section{Uso de ferramentas jornalísticas e educação não formal: estudo de caso no projeto RadioActive}

O projeto permite, desde o seu início, que os participantes escolham outras abordagens à rádio para além daquelas que estão tradicionalmente associadas à esfera informativa e às ferramentas jornalísticas. Sendo central para os objetivos do programa que exista um envolvimento dos participantes, é claro desde o início que eles podem participar com o que mais lhes agrada, incluindo funções de natureza técnica ou criação artística, entre outras. No entanto, a importância que o RadioActive dá à consciencialização dos participantes e respetivo grupo acerca dos seus contextos, implica sempre a identificação de histórias e temas, bem como a discussão de abordagens e motivações, num processo que é desencadeado e desenvolvido coletivamente. Foi neste contexto que as ferramentas oriundas do jornalismo se impuseram como catalisadoras de conhecimento. Assim, a reportagem, a entrevista e a notícia tornaram-se os géneros jornalísticos mais usados nos programas da RadioActive101 (RA101), a rádio online do projeto RadioActive. Porque é essencial que os participantes procurem o que está na base das suas vivências quotidianas, na essência da sua condição de jovens, e que possam tirar o máximo partido desses processos. A reportagem, o género jornalístico mais nobre na rádio, usada enquanto ferramenta de aprendizagem, implica um processo complexo que 
traz inúmeros ganhos aos participantes. Com efeito, a produção de uma reportagem implica que os participantes tenham de ser capazes de reconhecer o interesse de uma história, de definir o seu foco, de conceber um plano de trabalhos, de desenvolver a investigação documental acerca do tema, de delinear uma estratégia para o terreno - onde terão de contactar com o contexto da história e efetuar entrevistas, de selecionar o material captado e estruturar a narrativa, de idealizar e concretizar a imagem sonora, de escrever e de ler. A entrevista e o vox pop (este último, na verdade, uma forma composta da primeira) são inspirações que - quer no âmbito da reportagem, quer enquanto formatos autónomos - permitem que os participantes sejam ativos, planifiquem e façam perguntas. A capacidade de formular perguntas, a motivação e a competência para saber os motivos por detrás de uma história - no fundo, o querer saber porquê - é uma das capacidades mais interessantes que o projeto podia despertar. No mesmo sentido, a entrevista, ao ser essencialmente, um género de interação e diálogo, é socialmente vantajosa. Efetivamente, estes ganhos indiretos e inspirados nas ferramentas da ação jornalística são muito interessantes. A entrevista permite ainda que outras pessoas da comunidade (inclusive adultos) e de fora dela participem nas emissões e interajam mais com o centro juvenil mas também em concreto com a rádio. É um momento de partilha e de aprendizagem com os dispositivos, quer por parte dos participantes mais diretos, quer por parte dos mais indiretos. A entrevista, na rua, no centro e até no estúdio, constitui, para além disso, uma forma de as famílias se relacionarem com o projeto, como atesta uma das técnicas (centro 2) que destaca o impacto positivo que o RadioActive teve junto das famílias, que muitas vezes se deslocaram ao centro para ouvir as emissões ao mesmo tempo que era feita a emissão online.

Outro aspeto a considerar é a aprendizagem pela prática, sobretudo porque importa ter em mente que, mesmo estando simplesmente a utilizar ferramentas da esfera do jornalismo, essa prática é um processo complexo, ao qual se associam neste caso - as especificidades técnicas do trabalho na rádio. Nem tudo tem um resultado positivo na primeira tentativa e, como tal, as repetições de conteúdo, de escrita, de dicção, de estrutura acabam por gerar um valor educativo que ultrapassa a aprendizagem dentro dos limites exclusivos da rádio.

Eles aprendem muitas coisas na rádio, como fazer uma entrevista, como ser mais objetivo. Isso aprendemos na escola no 7.. ano quando estamos a dar o português com a parte da comunicação. Eles, com coisas tão simples como a rádio, [podem] fazer uma pergunta mais objetiva ou saber estruturar ou dizer que no programa passado fiz uma pergunta e ele não respondeu como eu queria. Agora vou ter de ser mais objetivo na questão para ter melhor resposta. [Responsável por TIC, centro 1, entrevista, janeiro de 2014]

Um outro aspeto digno de nota - e cuja importância neste artigo é central - é a transposição destas aprendizagens para o quotidiano, na linha da ideia já exposta de que os benefícios são mais relevantes do que as emissões per se (Nunes, 2008; Pinto, 2015). Sendo, habitualmente, um dos objetivos primordiais, este é também dos mais difíceis de alcançar, pois implica um trabalho continuado, 
uma capacidade e uma vontade de se apropriarem das aprendizagens e de as adequarem às necessidades escolares, por exemplo. Isto é evidente na dimensão tecnológica, já que um dos incentivos do projeto é precisamente o trabalho com ferramentas digitais. Um dos participantes no projeto refere-se à forma como a rádio se repercutiu na escola e na sua aprendizagem: "Melhorou bastante... até na escola e tudo... na disciplina de TIC eu aprendi... Quando o professor explicava coisas, algumas delas eu já sabia graças a nós termos feito alguns trabalhos para a RadioActive." [Rapaz, 17 anos, centro 2, entrevista, abril de 2014]

Estas aprendizagens também passam pela capacidade de trabalhar em equipa e pensar o quanto uma falha tem implicações no trabalho de todos:

Sim, porque se nós ficamos incumbidos de uma tarefa, sabemos que se não a concluirmos podemos deitar abaixo o trabalho de toda a edição, o trabalho de todos os outros. É uma responsabilidade. [Rapaz, 21 anos, centro 3, entrevista coletiva, abril de 2014]

Apesar de o jornalismo ter perdido a aura de romantismo que o caracterizava no início do século XX e de hoje alguns jovens tenderem a evitar os media tradicionais, a televisão continua a ser identificada como um meio primordial, como uma referência no domínio da informação e mesmo como motivo de conversa (notas de campo, maio e junho de 2013). Na realidade, os jovens vão tentando imitar, ainda que à sua maneira, as técnicas usadas pelos jornalistas, muito em especial o que veem na televisão. ${ }^{4}$

Eu gosto de fazer reportagens... às vezes não gosto muito de ouvir as reportagens da televisão porque são muito sérias, têm palavras muito difíceis, eu não percebo nada e é só política. [Rapariga, 12 anos, centro 2, entrevista, abril de 2014]

Esta influência dos modelos da informação televisiva sente-se noutros momentos. Muitas das imagens que os jovens trazem para o projeto acerca do que é uma reportagem ou uma entrevista são resultado da sua exposição sobretudo ao jornalismo televisivo. Esta mesma participante (rapariga, 12 anos, centro 2, entrevista, abril de 2014) é um exemplo disso. Ela reconhece que o vocabulário melhorou e que isso a ajudou na realização dos trabalhos escolares. Gosta de fazer entrevistas e destaca a importância de a mãe poder acompanhar o processo e mostrar-se satisfeita pela sua prestação na rádio. A experiência na RA101 permitiu-lhe perceber processos e opções técnicas, que antes via na televisão, mas cujos motivos e procedimentos não entendia. "E se calhar... quando vim para aqui e comecei a fazer entrevistas eu pensei porque é que na televisão tem aquela 'esponja' ...". Mais ainda, "quando via na televisão a fazer entrevistas pensava: 'será que eles chegam ao pé das pessoas e começam logo assim a fazer entrevistas?' ... Quando as pessoas têm pressa, eles [os jornalistas] têm de ficar ali até terminar a entrevista,

4 Os jovens disseram que não ouvem rádio na internet, mas especificamente no iTunes e no contexto analógico (notas de campo, 31 de maio de 2013). 
aguentar a pessoa...?". "Agora", diz a mesma entrevistada, "percebo melhor esse processo". Efetivamente, perceber o fluxo de preparação e realização de entrevistas permitiu-lhe ainda ser mais desinibida em contexto social escolar. Mas, sobretudo, deu-lhe uma maior capacidade para falar com pessoas que lhe eram desconhecidas, às quais tinha de se dirigir de forma educada e fazer perguntas, estando sempre preparada para, eventualmente, lidar respeitosamente com uma recusa: "Tinha de pedir... dizer que era da RadioActive... Pedir e se eles dissessem que sim, entrevistava, se dissessem que não, 'então obrigada'." [Rapariga, 12 anos, centro 2, entrevista, abril de 2014]

Outra participante de 17 anos destaca precisamente o facto de a realização de entrevistas a ter tornado mais desinibida, com melhorias concretas na comunicação, na motivação e na autoconfiança. Estes foram, aliás, aspetos muito valorizados pelos participantes entrevistados e ainda pelos técnicos que com eles trabalham. Dois dos participantes do centro de Coimbra (centro 3) referem-se precisamente ao mesmo aspeto:

Se nós fazemos um bom trabalho, [é] óbvio que estamos aplicados, logo vamos ter mais motivação para continuar a fazer esse trabalho. A autoconfiança acho que não é tão importante como a motivação. [Rapaz, 18 anos, centro 3, entrevista coletiva, abril de 2014]

Nós somos pessoas que nunca tinham falado numa rádio e hoje conseguem falar e fazer uma entrevista. Isso é a motivação para continuar a aprender... e a autoconfiança porque não a tinham e eram tímidos. [Rapaz, 23 anos, centro 3, entrevista coletiva, abril de 2014]

A coordenadora do centro 2, olhando para um ano de atividades de rádio, refere-se ao facto de os jovens terem aprendido a olhar mais para fora do seu mundo e a saber interagir melhor com essa mesma comunidade:

Na fase inicial os miúdos também tinham dificuldades para se apresentarem e dizer quem é que são... e ao longo do tempo eles já sabem: "somos do projeto tal", já conseguem explicar. Isso é uma barreira que está conquistada e ultrapassada, neste caso. Nós estamos a fazer uma comparação desde o ano passado para este ano, relativamente à relação que eles conseguem fazer na rua e à própria abordagem, eles melhoraram, sem dúvida. [Grupo focal, abril de 2014]

Idêntica perceção tem a responsável no mesmo centro pelas atividades da rádio:

Há coisas simples como a boa educação quando se aborda alguém. Como é que se aborda, não é? Não se aparece à pessoa assim de surpresa, tem que se dizer "olá, eu sou o não sei quem" e isso são competências que nós achamos essenciais para o resto da vida deles. Não é para serem locutores de rádio, é para todas as situações, não é? [Grupo focal, abril de 2014] 
Os técnicos que participaram no grupo focal têm afirmado que este desafio de transpor o que os jovens aprendem na rádio para a vida quotidiana é um dos maiores e também um dos mais difíceis. Na realidade, por vezes eles interiorizam bem o papel de jornalistas - assumindo papéis diversos nas suas interações sociais, na linha de Goffman (1993), que desenhou uma conceção dramatúrgica da vida social que colocou a ênfase nos papéis que os indivíduos assumem face a outros nas suas interações sociais -, de técnicos de rádio ou locutores. Contudo, a passagem dessa aprendizagem sobre o papel de "quem sabe fazer" para contextos sociais mais vastos requer um trabalho continuado. Apesar das melhorias na postura e da maior autoconfiança (fora dos contextos do centro e da escola e também com estranhos), neste último caso ainda há progresso a fazer. Por outras palavras, a assimilação de uma determinada confiança nos seus desempenhos não é alheia aos diferentes contextos em que ocorre e precisa de ser validada e revalidada nos contextos mais familiares para posteriormente chegar aos mais estranhos.

Um outro fator essencial no desenvolvimento do projeto foi a apropriação pessoal e grupal da atividade. A rádio deixa de ser apenas a rádio e passa a ser a nossa rádio, como atesta uma das técnicas do centro 2:

ao fim destas emissões eles começam a dizer "a nossa rádio" e acho que é um bom sinal. Já integraram e sabem que isto faz parte. Há dias em que não lhes apetece e acham uma chatice, mas percebem que tem que acontecer e que isso é uma coisa boa que deve persistir. Eles sentem até responsabilidade: "então quando é que é?", "há alguma coisa para ver?" [Grupo focal, abril de 2014]. Já houve alturas em que uns disseram “há alguma coisa para fazer?", "é preciso gravar textos?”, “é preciso qualquer coisa?”.

A mesma responsável afirma: "por exemplo, até houve as visitas à rádio... eles já percebem... No outro dia houve duas meninas que me chamaram e disseram 'não te esqueças de nós... as repórteres', portanto já se intitulavam" [grupo focal, abril de 2014], remetendo novamente para a assunção de papéis da esfera jornalística, como resultado da utilização destas ferramentas num grupo de trabalho.

De facto, no âmbito do RadioActive foram realizadas visitas a estações de rádio e televisão e esses momentos foram vividos com muita intensidade. Por um lado, são atividades que permitem sair de dinâmicas fechadas; mais do que isso, contribuem para um maior conhecimento sobre realidades concretas de trabalho, através da interação com jornalistas profissionais, permitindo estabelecer paralelismos entre as rotinas profissionais do jornalismo e o uso das ferramentas jornalísticas que eles fazem na RA101. A compreensão das várias fases envolvidas, sugestionadas pelas rotinas profissionais de produção jornalística, acaba por revelar dinâmicas de leitura das representações da realidade que os públicos nem sempre conseguem compreender. Desta forma, há um processo de conhecimento e questionamento crítico tendente a uma literacia mediática, na aceção de Lopes (2015).

Sistematizando, o projeto envolve três grandes e essenciais grupos de tarefas - e áreas de competências enunciadas anteriormente: a área do jornalismo e da produção de conteúdos, a atividade técnica e a dimensão organizacional. Até ao 
momento, o campo jornalístico é o que tem tido mais participantes e mais sucesso, também porque os jovens estão habituados a ver notícias, estando por isso mais familiarizados com as expectativas que se associam à assunção desse papel. Isso mesmo pôde verificar-se aquando da avaliação do primeiro ano:

Coordenadora de centro - Eles veem como fazem os jornalistas ou...

Responsável pela rádio - Podem fazer um projeto de imitação...

Coordenadora de centro - Um projeto de imitação, um jogo do faz de conta, de brincar ao jornalismo... ou brincar às pessoas que fazem entrevistas... O processo de organizar, não é um processo de faz de conta... Eu acho que na parte inspirada no jornalismo também têm encarado melhor porque, para eles, também podem... [...] estar a interiorizar o papel e brincar ao faz de conta, mas têm coisas... E aquilo, realmente, irá funcionar para mais tarde, irá ser colocado num programa. [Grupo focal, abril de 2014, centro 2]

Considera-se, pois, que os jovens poderão ser mais criativos do que os adultos, até pelo que representam e pelo facto de poderem catapultar ideias novas. Mas, na realidade, nem sempre é isso que os técnicos encontram no terreno. Por isso mesmo, as imagens que têm sobre o jornalismo são ainda mais relevantes, pois permitem ultrapassar de certa forma essa questão.

Tradicionalmente temos a ideia de que os jovens são muito criativos; são, mas também são muito formatados. São sujeitos a muitas influências externas, os media, o meio envolvente, a família, às vezes mais do que aquilo que esperamos, não sugerem muitas ideias criativas, não quer dizer que elas não existam, mas acabam por adaptar o discurso e acabam sempre nas mesmas coisas. Isso é um desafio. Às vezes somos nós adultos a tentar espicaçar a criatividade infantil [ri-se] ou juvenil; não devia ser assim. [Responsável pela rádio no centro 2, grupo focal, abril de 2014]

O que está aqui em causa é também o facto de estas formas de aprendizagem se fazerem num ambiente mais descontraído, em que os jovens têm capacidade de decisão e de manobra em relação ao que é proposto e decidido. Quando estão em causa jovens e locais onde há um maior risco de exclusão ou exclusão já efetiva do sistema de ensino, esta possibilidade de estarem perante uma educação não formal torna-se ainda mais relevante.

Se repararmos, estamos numa zona vulnerável, é uma zona habitacional com muitos bairros, com miúdos que normalmente são um bocado reticentes à educação formal e se calhar a única forma que temos para chegar até eles é com este tipo de educação não formal que é muito mais fácil de se aplicar, é muito mais apelativa. Os conhecimentos não são tão profundos como na formal, mas consegue-se dar algumas luzes para que percebam as coisas e também podemos dar algumas coisas não tão chatas mas que despertem o bichinho para eles procurarem mais as coisas. A educação informal é essencial aqui pois temos muito absentismo escolar. [Responsável por TIC, centro 1, entrevista, janeiro de 2014] 


\section{Conclusões}

Os resultados conseguidos no RadioActive apontam para a importância que a inspiração no jornalismo e a utilização de técnicas oriundas dessa esfera informativa podem ter como ferramentas educativas, particularmente tendo em conta a sua ligação às comunidades, em contextos da vida quotidiana e de aprendizagem pela prática. Pensando nas duas questões de partida, relativas ao tipo de repercussão que a prática de técnicas do jornalismo pode ter como ferramenta educativa junto destas comunidades juvenis e ainda quanto aos papéis assumidos pelos jovens que participam no projeto e respetiva repercussão no quotidiano, identificamos pontos de ligação positiva, que contribuem para uma melhoria de competências desses jovens nas suas esferas de ação, designadamente na escola e nas interações sociais de forma geral.

Esses ganhos são, porém, mais evidentes quando os participantes se encontram dentro do espaço da prática da rádio do que quando se deslocam para outros contextos, nomeadamente os do seu quotidiano, nos quais o papel real assumido já não é o do jornalista. É nesse sentido que consideramos que a apropriação de procedimentos e papéis já aceites por todos pode conduzir a uma expansão e afirmação pessoais progressivas. Note-se, porém, que essa expansão tem subjacente uma adoção inicial de uma outra identidade, cujo conforto da apropriação resulta da aceitação comum pelo grupo daquilo que se espera que esse papel represente. Essa primeira saída da zona pessoal de conforto, adotando um modelo (porventura nunca antes pensado fora deste contexto), é o primeiro passo para uma progressiva adoção das aprendizagens da rádio na vida quotidiana.

Apesar de ser evidente que os dois anos de investigação ainda são insuficientes para, de forma ampla, indicar alterações profundas e estruturantes na vida destes jovens participantes, há sinais positivos de que a vivência de experiências emotivas na comunidade pode contribuir para o bem-estar social e para a facilitação de pontes de saber. Além disso, é tão importante situar, como acontece com o RadioActive, os participantes e os investigadores num nível de coaprendizagem mútua, ultrapassando assim os limites da educação formal e da própria investigação tradicional, potenciando a aprendizagem e o conhecimento pela prática (Underwood, Parker e Stone, 2013).

Estas considerações apontam para a necessidade de apostar em projetos de continuidade e sustentados, sobretudo em comunidades mais fragilizadas por processos de exclusão. Nestes casos, a opção por soluções integradas e de continuidade pode ser mais benéfica do que a adoção de soluções focalizadas e de curta duração. Do ponto de vista das empresas jornalísticas, abre-se também aqui a possibilidade de serem parceiros em processos de mudança social e até proporcionarem públicos mais interessados em notícias.

\section{Referências bibliográficas}

Barbalho, Alexandre (2008), "A criação está NoAr: Juventude, mídia e cidadania", em Bruno Fuser (org.), Comunicação para a Cidadania. Caminhos e Impasses, Rio de Janeiro, E-papers, pp. 163-178. 
Brinca, Pedro (2014), “'Setúbal na Rede’ promove prática do jornalismo em escolas - a educação para os media como forma de promoção da cidadania", em Sérgio Gomes da Silva e Sara Pereira (coords.), Atas do 2.․ㅡ Congresso "Literacia, Media e Cidadania", Lisboa, Gabinete para os Meios de Comunicação Social, pp. 486-492.

Brites, Maria José (2015), Jovens e Culturas Cívicas. Por entre Formas de Consumo Noticioso e de Participação, Covilhã, Livros LabCom, disponível em:

http://www.labcom-ifp.ubi.pt/ficheiros/20150129-2015_01_jovens_culturas_civicas. pdf (última consulta em outubro de 2014).

Brites, Maria José, Ana Jorge, e Sílvio Correia Santos (2014), “RadioActive: um projeto europeu de rádio online”, em I. Eleá (org.), Agentes e Vozes. Um Panorama da Mídia-Educação no Brasil, Portugal e Espanha (Yearbook 2014), Gotemburgo, Nordicom, pp. 181-186.

Buckingham, David (2012 [2003]), Media Education. Literacy, Learning and Contemporary Culture, Cambridge, Polity Press.

Chaskin, Robert J. (2013), "Theories of community”, em Marie Weil, Michael S. Reische e Mary L. Ohmer (orgs.), The Handbook of Community Practice, Thousand Oaks, Londres, Nova Deli e Singapura, Sage Publications, pp. 105-122 (2. a edição).

Dahlgren, Peter (2009), Media and Political Engagement. Citizens, Communication, and Democracy, Cambridge, Cambridge University Press.

Dahlgren, Peter (2013), The Political Web, Londres, Palgrave Macmillan.

ENPA - European Newspaper Publishers' Association (2013), What's Your News?, Bruxelas, ENPA.

Freire, Paulo (2010), Pedagogia da Autonomia. Saberes Necessários à Prática Educativa, São Paulo, Editora Paz e Terra.

Goffman, Erving (1993), A Apresentação do Eu na Vida de Todos os Dias, Lisboa, Relógio d'Água.

Hobbs, Renee, Henry Cohn-Geltner, e John Landis (2011), “Views on the news: media literacy empowerment competencies in the elementary grades", em Cecilia Von Feilitzen, Ulla Carlsson e Catharina Bucht (orgs.), Yearbook 2011 - New Questions, New Insights, New Approaches. Contributions to the Research Forum at the World Summit on Media for Children and Youth 2010, Gotemburgo, The International Clearinghouse on Children, Youth and Media / Nordicom / University of Gothenburg, pp. 43-56.

Kaplún, Mario (2011), "Processos educativos e canais de comunicação", em Adílson Odair Citelli e Maria Cristina Castilho Costa (orgs.), Educomunicação. Construindo Uma Nova Área de Conhecimento, São Paulo, Paulinas, pp. 175-186.

Lahni, Cláudia Regina, e Fernanda Coelho (2008), “A comunicação ao serviço da cidadania e da identidade de adolescentes", em Bruno Fuser (org.), Comunicação para a Cidadania. Caminhos e Impasses, Rio de Janeiro, E-papers, pp. 209-226.

Lewis, Seth C., Kelly Kaufhold, e Dominic L. Lasorsa (2010), “Thinking about citizen journalism", Journalism Practice, 4 (2), pp. 163-179.

Livingstone, Sonia (2004), "Media literacy and the challenge of new information and communication technologies", The Communication Review, 7 (1), pp. 3-14.

Livingstone, Sonia, e Ellen Helsper (2007), “Gradations in digital inclusion: children, young people and the digital divide", New Media $\mathcal{E}$ Society, 9 (4), pp. 671-696. 
Lopes, Paula (2015), “Avaliação de competências de literacia mediática: instrumentos de recolha de informação e opções teórico-metodológicas", em Ana Jorge, Maria José Brites e Sílvio Santos (orgs.), Educação para os Media na Era Digital, número especial de Media $\mathcal{E}$ Jornalismo, 15 (27), Imprensa da Universidade de Coimbra, DOI: http://dx.doi.org/10.14195/2183-5462_27_2

Mesquita, Mário (2003), “As tendências comunitaristas no jornalismo cívico", em Nelson Traquina e Mário Mesquita (orgs.), Jornalismo Cívico, Lisboa, Livros Horizonte, pp. 19-27.

Meyers, Eric M., Ingrid Erickson, e Ruth V. Small (2013), “Digital literacy and informal learning environments: an introduction", Learning, Media and Technology, 38 (4), pp. 355-367.

Mihailidis, Paul (2012), "Introduction: news literacy in the dawn of a hypermedia age", em Paul Mihailidis (org.), News Literacy: Global Perspectives for the Newsroom and the Classroom, Nova Iorque, Washington, DC, Berna, Frankfurt, Berlim, Viena e Oxford, Peter Lang, pp. 1-20.

Milner, Henry (2009), “Does civic education boost turnout?", em Murray Print e Henry Milner (orgs.), Civic Education and Youth Political Participation, Roterdão, Boston e Taipei, Sense Publishers, pp. 187-196.

Moeller, Susan (2009), "Media literacy 101: power to the people", consultado a 30 de agosto de $2011 \mathrm{em:}$

http://www.huffingtonpost.com/susan-moeller/media-literacy-101-power_b_182112.html

Nunes, Márcia Vidal (2008), “Novas tecnologias e cidadania: Internet como fator de politização ou de adequação das comunidades excluídas ao sistema produtivo?", em Bruno Fuser (org.), Comunicação para a Cidadania. Caminhos e Impasses, Rio de Janeiro, E-papers, pp. 105-122.

Paula, Patrícia Filipa da Mota (2012), Rádios Comunitárias. Em Prol da Comunicação para o Desenvolvimento. Perspectiva Comparada. Guiné-Bissau e Moçambique, Lisboa, ISCTE-IUL, tese de doutoramento apresentada à Escola de Sociologia e Políticas Públicas.

Pereira, S., M. Pinto, e P. Moura (2015). Níveis de Literacia Mediática. Estudo Exploratório com Jovens do $12^{\circ}$ Ano, Braga, CECS.

Pinto, Manuel (2014), “O trabalho em rede na definição de uma política de literacia mediática", em Ilana Eleá, Agentes e Vozes. Um Panorama da Mídia-Educação no Brasil, Portugal e Espanha, Gotemburgo, Nordicom, pp. 157-166.

Pinto, Manuel (2015), "Foreword: literacy to navigate", em Sara Pereira (org.), Digital Literacy, Technology and Social Inclusion, Famalicão, Húmus, pp. 19-22.

Ravenscroft, Andrew (2011), “Dialogue and connectivism: a new approach to understanding and promoting dialogue-rich networked learning", International Review of Research in Open and Distance Learning, 12 (3), disponível em: http://www.irrodl.org/index.php/irrodl/article/view/934/1676 (última consulta em outubro de 2014).

Reader, Bill (2012), “Community journalism”, em Bill Reader e John A. Hatcher (orgs.), Foundations of Community Journalism, Thousand Oaks, Londres e Nova Deli, Sage Publications, pp. 3-20. 
Stephenson, Becky Herr (2013), "New media and learning”, em Dafna Lemish (org.), The Routledge International Handbook of Children, Adolescents and Media, Londres e Nova Iorque, Routledge, pp. 410-416.

Tomé, Vitor (2014), “De ‘Um Dia com os Media' à 'Semana com os Media': iniciativas em escolas e do jornal local Reconquista, de Castelo Branco", em Sérgio Gomes da Silva e Sara Pereira (coords.), Atas do 2.․ㅡ Congresso "Literacia, Media e Cidadania", Lisboa, Gabinete para os Meios de Comunicação Social, pp. 470-485.

Tufte, Thomas (2015), Comunicación para el Cambio Social. La Participación y el Empoderamiento como Base para el Desarrollo Mundial, Barcelona, Icaria.

Underwood, Charles, Leann Parker, e Lynda Stone (2013), “Getting it together: relational habitus in the emergence of digital literacies", Learning, Media and Technology, 38 (4), pp. 478-494.

Van Dijk, Jan A. G. M., e Alexander J. A. M. Van Deursen (2014), Digital Skills. Unlocking the Information Society, Nova Iorque, Palgrave Macmillan.

Weerasinghe, Harshani (2012), "Preparing for the community broadcasting", em K. Seneviratne (org.), Peoples' Voices, Peoples' Empowerment. Community Radio in Asia and Beyond, Singapura, AMIC - Asia Media Information and Communication Centre, pp. 335-340.

Wenger, Etienne, Nancy White, e John D. Smith (2009), Digital Habitats. Stewarding Technology for Communities, Portland, CPsquare.

WAN-IFRA - World Association of Newspapers and News Publishers, http://www.wan-ifra.org/microsites/youth-engagement-news-literacy (consultado a 20 de junho de 2014).

\section{Documento oficial}

Recomendação do Parlamento Europeu e do Conselho, de 18 de dezembro de 2006, sobre as competências essenciais para a aprendizagem ao longo da vida.

Maria José Brites (corresponding author). Professora auxiliar na Universidade Lusófona do Porto e investigadora no Centro de Estudos de Comunicação e Sociedade / Universidade do Minho, Porto e Braga, Portugal.

E-mail: britesmariajose@gmail.com

Sílvio Correia Santos. Professor auxiliar convidado na Faculdade de Letras da Universidade de Coimbra, Coimbra, Portugal.

E-mail: silviocorreiasantos@gmail.com

Ana Jorge. Professora auxiliar convidada na Faculdade de Ciências Humanas da Universidade Católica Portuguesa e investigadora do CICS.Nova, Lisboa, Portugal. E-mail: anajorge@fch.lisboa.ucp.pt 
Daniel Catalão. Doutorando na Faculdade de Engenharia da Universidade do Porto, docente na Universidade Lusófona do Porto e jornalista/apresentador na RTP, Porto, Portugal. E-mail: danielcatalao@gmail.com

Receção: 28 de outubro de 2014 Aprovação: 18 de setembro de 2016 